the Validation of Alternative Methods: a small laboratory in Ispra, Italy, devoted to finding kinder and more-refined toxicity tests that would require fewer, or no, animals. That work has begun to pay off. For example, the notorious $\mathrm{LD}_{50}$ test is required, which identifies the dose that kills half of the tested animals, now involves around ten rats rather than 45 . And instead of looking for a dose that causes outright (and painful) skin allergy in guinea pigs, toxicologists can now monitor mice for the painless swelling of lymph nodes, the first sign of allergy.

These are the only two animal tests required for chemicals produced in relatively small quantities (1-10 tonnes a year). Those produced in smaller quantities require no animal testing at all. Not so happily, however, the refinements will have little effect when it comes to chemicals produced in larger volumes. $\mathrm{REACH}$ will require many more tests on such compounds, including, in some cases, their effects on reproduction and fertility, which use 3,000 animals per chemical.

\section{Linking up development}

\section{An initiative to link scientists in the poorest nations with colleagues around the world deserves support.}

n September 2000, the United Nations pledged to achieve eight Millennium Development Goals by 2015 — among them, halving extreme poverty, providing primary education to all and stopping the spread of HIV/AIDS. The goals have spurred unprecedented efforts by countries and development agencies alike. But some of those efforts, such as the controversial One Laptop Per Child Project, which is widely seen as a developed-world solution to a developing-world issue, should also serve as a warning of the illusion that the problems of development can be solved with technological quick fixes.

That circumspection should be borne in mind by Scientists Without Borders - an initiative launched with great fanfare on 12 May by the New York Academy of Sciences in partnership with the UN Millennium Project. The initiative aims to address health and other issues in developing countries by using the Internet to bring together scientists from different countries and fields.

The academy argues that the initiative will "create a broad array of synergistic linkages among the many bold but heretofore unconnected efforts to generate science-driven, sustainable development in the poorest of the poor communities". As a result, it predicts, universities in rich and poor nations will volunteer to work together to train local staff, and people and institutions will learn from one another and collaborate on development issues in a more interdisciplinary and integrated fashion.

The caveat, of course, is that better communication between scientists alone cannot magically transform Africa, or any other part of the developing world. And although the virtual Scientists Without Borders has gained the support of some impressive partners - including France's Institut Pasteur and the American Society for Cell Biology in Bethesda, Maryland - it has only one full-time staff member, and has raised US\$1 million. As such, it has little in common - aside from

Beyond REACH, moreover, the 2003 amendment to the EU Cosmetics Directive will soon add even more time pressure: an end to acute toxicity testing of cosmetics (including soaps and shampoos) in animals by 2009 , and the longer and more involved repeat-dose testing by 2013 . Scientists consider the latter deadline to be hopelessly unachievable. There is simply no way in the foreseeable future that they will be able to model and predict all the ways that a foreign molecule might interact over time with the hundreds of types of tissues in the human body.

Yet that is all the more reason to put some serious effort into tackling the problem. Revolutionizing regulatory toxicology won't be cheap and it won't be quick, although systems biology — the integration of genomics, proteomics and all the other '-omics' - could prove to be a particularly powerful ally. But it should be a priority. And, as shown by the cosmetics directive's unrealistic deadline (fortunately renegotiable in 2011), scientists have to be brought into policy decisions at the beginning, and listened to carefully.

its name - with the operational agency Doctors without Borders (Médecins Sans Frontières), which has a $€ 569$ million (US\$ 896 million) annual budget, and thousands of staff around the world.

That said, however, we hope that the academy is right, and that Scientists Without Borders will rapidly become the Facebook of development. The initiative certainly deserves scientists' full support for its efforts to boost the capacity of researchers in poorer countries. Consider its first initiative: to create an online database in which scientists and institutions can register their profiles, and so connect with others who share similar interests. Yes, many databases and social networks already exist for scientists. But Scientists Without Borders is unique in its commitment to raise the visibility of research in developing countries, and to compile an inventory of who is doing what specifically limited to those who have expressed an interest in cooperating. This in itself is a worthwhile exercise.

"Scientists should nurture this fledgling initiative."

The database will also tap user profiles to match research needs with available resources, say, or to announce the availability of volunteer work and research collaborations - although it is still far from clear how this will work in practice.

Scientists Without Borders faces a wider challenge given its coverage of all disciplines and sectors, as it makes it difficult for experts to pick out the information that is relevant to them. Online communities of practice tend to flourish around bottom-up approaches that generate centres of common interest that keep members active and coming back for more. But it is encouraging that the organizers seem keen for users to suggest changes to the Scientists Without Borders platform to meet their needs. Experience elsewhere shows that demand for social networks is critically dependent on them satisfying real user exigencies.

Most importantly, the initiative has generated hope. As one new user told Nature, it has for the first time provided him with a space to "put my skills on the radar of those directly involved in projects in the developing world; I hope I can contribute in some way." We would encourage scientists to sign up and participate, and nurture this fledgling initiative. 